\title{
A QUESTÃO RUSSA: SEU LUGAR NAS REFLEXÕES DE VANGUARDA SOCIALISTA*
}

Isabel Maria LOUREIRO**

\begin{abstract}
RESUMO: Vanguarda Socialista, jornal editado por Mário Pedrosa no Rio de Janeiro, de 1945 a 1948, elabora uma proposta política socialista e democrática como alternativa à concepção bolchevique, que acredita superada pela história. Nessa medida, a "questão russa" encontra-se no centro das preocupações do grupo. Este artigo procura não só analisar a explicação do jornal para as origens da burocracia na URSS, mostrando as contradições que a perpassam, como também estabelecer a filiação do grupo às idéias de Rosa Luxemburgo, na tentativa de esclarecer as referidas contradiçòes.
\end{abstract}

UNITERMOS: Revolução; leninismo; stalinismo; burocracia; socialismo; democracia.

Ao Luiz Araújo Prado, amigo.

In memoriam.

Os homens de minha idade que não se empolgaram pela Revolução Russa... alguma coisa lhes falta.

\section{Mário Pedrosa}

Para Vanguarda Socialista, a reflexão sobre o caráter da Revolução Russa, considerada "o maior acontecimento do século",***, e sobre as causas da sua degenerescência burocrática constitui a pedra de toque, tanto do ponto de vista teórico quanto prático, para se determinar com clareza o que é o socialismo e qual a via para lá chegar. É pela compreensão desse processo que se pode definir o stalinismo "separando o que ali foi ditado pela lei de ferro da necessidade objetiva e o que é conjuntural ou deformação evitável",**** e o Estado russo atual, clarificação que para Vanguarda Socialista representa o primeiro passo para a constituição de uma alternativa de esquerda ao "Estado totalitário",***** implantado na Rússia. Com tal intuito, Mário Pedrosa realiza uma série de palestras, publicadas entre 12 de abril e 28 de junho de 1946. A partir dessa ocasião são elaboradas teses, sob o título de "Novos Rumos”, vistas pelo grupo como

\footnotetext{
* Este artigo constitui o $1 .^{\circ}$ capitulo de minha dissertação de mestrado Vanguarda Socialista (1945-1948), Um episódio de ecletismo na história do marxismo brasileiro - Faculdade de Filosofia, Letras e Ciências Humanas, Universidade de São Paulo - 1984.

** Departamento de Filosofia - Faculdade de Educação, Filosofia, Ciências Sociais e da Documentação - UNESP — 17500 - Marilia - SP.

*** Vanguarda Socıalista(VS), “Diretivas”, manifesto lançado no primeiro número do jornal, 31/8/45.

***** Id., Ibid.

***** VS, "Novos Rumos", 20/9/46.
} 
uma primeira contribuição teórica para a constituição de um partido socialista no Brasil.*

Ao tentar detectar as origens da burocracia na Rússia, Mário Pedrosa diz concordar com Lenin, para quem os primeiros sinais de degenerescência burocrática se verificam já em 1919, sendo constatados no VII Congresso Pan-Russo dos Sovietes. Contudo, a questão só é abordada em toda a sua plenitude no decorrer do X Congresso do PCUS, em março de 1921. Nessa ocasião, diz Pedrosa, “a burocracia, já como um grupo social à parte, embora ainda sem independência social e política, tomava cada vez mais caracteres próprios.",

Nesse artigo, de 26 de junho de 1946, Pedrosa refere-se às frações surgıdas no interior do partido - Oposição do Centralismo Democrático e Oposição Operária - e cita a plataforma desta última a qual traduz o profundo descontentamento sentido pela parte mais consciente do proletariado em relação à política bolchevique**. A Oposição Operária, diretamente ligada à massa trabalhadora e aos sindicatos, toma consciência de que nos três anos de guerra civil em que as instituições soviéticas foram criadas, a classe operária, enquanto classe, é cada vez menos levada em consideração pelo governo bolchevique. Segundo Pedrosa, a Oposição Operária é fruto da "separação cada vez maior entre as massas que primeiro que tudo precisavam de comer e a base do partido, de um lado, e, de outro, os vértices do partido, da burocracia e do aparelho de Estado.",***

Para Mário Pedrosa, Lenin é o grande líder da Revolução de Outubro, o político que procura compreender e resolver os problemas inesperados que a conjuntura coloca. Nesse sentido, é um crítico alerta e perspicaz da burocracia nascente. Porém, as medidas que toma para destruí-la são inócuas, porque também burocráticas. Ao mesmo tempo que constata que toda a sociedade soviética está sendo corroída pela "gangrena burocrática" que começa mesmo a atingir a vida do partido, toma a decisão, apoiada pelo X Congresso, de proibir as frações no interior da organização: “A justificativa para a proibição eram as tremendas dificuldades por que passava o país (insurreição de Kronstadt, de Tambov, etc.); como tantas vezes acontece, o que foi ditado por circunstâncias fortuitas, o que devia ter apenas validade provisória, tornou-se eterno sob a forma do monolitismo staliniano'. **** Ou seja, denunciava-se o perigo da burocracia e, simultaneamente, adotava-se uma medida burocrática para resolver um problema muito mais prof undo, reforçando-se assim o que se queria combater.

\footnotetext{
* Embora VS funcione no seu primeiro ano muito mais como uma tribuna livre do que com uma linha editorial seguida por todos os articulistas, há um corpo de proposiçỏes básicas aceito por todos e que poderia ser resumido da seguinte maneira: a Rússia é um novo Estado opressor, o advento do socialismo só será possivel através da luta consciente dos trabalhadores organizados pela base, a defesa do partido-classe contra o partido-vanguarda. E, no caso do Brasil, a crítica à politica de colaboração de classes do PCB, à ditadura varguista e o apoio à candidatura Eduardo Gomes. Com variaçōes aqui e ali essa é a linha adotada por todos os colaboradores, linha dada pelo diretor do jornal, Mário Pedrosa, nos editoriais, quase todos de sua autoria. Por esse motivo a identificação constante, neste artigo, entre Mário Pedrosa e VS.

** Castoriadis, na sua introdução ao texto de Alexandra Kollontai, A Oposição Operária, ambos publicados em Socialisme ou Barbarie, n. ${ }^{\circ} 35$ de janeiro de 1964, é taxativo quanto à importância da Oposição Operária na crítica à burocracia nascente. Diz que antes de mais nada o texto é importante "pelas indicações diretas que fornece sobre at atitudes e as reações dos Operários russos face à política do partido bolchevique. Em seguida, e sobretudo, mostrando que uma larga fração da base operária do partido tinha consciência do processo de burocratização em curso, e se erguia contra ele. Não é mais possivel, após ter lido este texto, continuar a apresentar a Rússia de 1920 como um caos, um amontoado de ruinas, onde o proletariado se encontrava pulverizado e onde os únicos elementos de ordem eram o pensamento de Lenin e a 'vontade de ferro' dos bolcheviques. Os Operários queriam alguma coisa e mostraram-no, no partido pela Oposição Operária, fora do partido pelas greves de Petrogrado e a revolta de Kronstadt. Foi preciso que uma e outra fossem esmagadas por Lenin e Trotsky para que Stalin pudesse, em seguida, triunfar". (2, p. 390).

*** VS, $26 / 4 / 46$.

**** VS, 28/6/46. Pedrosa diz que os bolcheviques se viram na “necessidade dolorosa” de liquidar Kronstadt.
} 
Embora a burocratização da sociedade soviética, do Estado e do partido tenha começado no decorrer da guerra civil, de acordo com Mário Pedrosa ela era ainda incipiente neste primeiro momento. É a adoção da NEP que permitirá o seu verdadeiro desabrochar mas, mesmo aqui, não era ainda uma classe: tinha saído do proletariado que fizera a Revolução de Outubro, era politicamente neutra, servindo tanto o setor privado quanto o estatal*. Ou seja, a burocracia só se torna uma classe com interesses próprios a defender quando, com a derrota da Oposição de Esquerda e de Direita, vence a tendência de Stalin no interior do partido.

Pedrosa lembra que a tendência stalinista nasceu sobre a ideologia do socialismo num só país, representando a burocracia do partido e a do Estado. De 1927 a 1929 essa nova corrente destruiu a velha base revolucionária e proletária do partido e iniciou a fase nacional de industrialização feita pelo Estado sob os imperativos da racionalidade taylorista. Os kulaks e os "nepmem" foram expropriados, os sindicatos liquidados, as frações ou embriões de frações esmagados. Surge a ideologia do partido monolítico, do chefe infalível. Os sindicatos passam a lutar pelo aumento do ritmo da produção, aparece o stakanovismo, a exploração intensiva do trabalhador que passa a ser premiado caso produza mais. Tem início a coletivização forçada.

De acordo com Pedrosa, foi com a industrialização acelerada, levada a cabo por Stalin no final dos anos 20, que a burocracia cresceu. Surgiram os especialistas apenas interessados em realizar os planos impostos sob pena de fuzilamento ou afastamento das funções. Como os interesses das massas eram menosprezados, tornava-se necessário dar estímulo pessoal à camada de burocratas para que Stalin tivesse um ponto de apoio na população. Criou-se a especialização intensiva das funções tanto no aparelho de Estado quanto no de produção, dividindo-se a própria burocracia em duas camadas: baixa e alta, aumentando cada vez mais a distância entre o trabalhador médio e os vértices da burocracia estatal e industrial. O lucro foi reinstaurado como maneira de estimular a produção**. Em suma, o programa da Oposição de Esquerda, defensor da industrialização acelerada, aplicado com atraso por Stalin, não levou à criação de uma economia socialista de caráter democrático mas a um "regime totalitário de uma burocracia onipotente" $* * *$

Tanto o programa da Oposição de Direita (favorável ao fortalecimento dos camponeses, o que levaria à restauração do capitalismo, segundo Pedrosa), quanto o da Oposição de Esquerda se revelaram inadequados à realidade, o que, em parte, se deveu à ilusão de ambas que acreditavam estar a Revolução de Outubro ainda de pé, o Estado soviético ser ainda operário e o proletariado russo, tal como ressurgiu, ser ainda capaz de exercer controle sobre o Estado. Diz Mário Pedrosa que o proletariado que fizera a Revolução de Outubro fora substituído por outro, mais "novo, mais inconsciente, manobrado pela burocracia"**** que se implantou no vértice das camadas sociais substituindo-se à burguesia, não para implantar o socialismo, mas para industrializar a Rússia. Na medida em que o controle dos trabalhadores inexistia, o governo sentiu-se forte o bastante para promover a industrialização acelerada e a coletivização forçada às custas dos interesses imediatos das massas. Se, num primeiro momento, a burocracia (que, de acordo com Pedrosa, Lenin queria controlar) era ainda uma camada neutra e amorfa, sob Stalin ela passa a dirigir a produção, a controlar o Estado e a defen-

*VS, $31 / 5 / 46$.

**VS, $3 / 5 / 46$.

***VS, $10 / 5 / 46$

**** VS, $10 / 5 / 46$ 
LOUREIRO, I.M. - A questão russa: seu lugar nas reflexões de Vanguarda Socialista. Trans/Form/Ação, São Paulo, 8:28-38, 1985 .

der seus privilégios. "A burocracia se classiciza. Na base de quê? Precisamente dessa extrema centralização do aparelho econômico e do fato de o Estado passar a possuir todos os meios de produção." * Segundo Pedrosa, na opinião de Lenin, essa extrema centralização nas mãos do Estado levaria ao suicídio da revolução de fato ocorrida. Morreu a revolução proletária, o comunismo, mas não o Estado que dela surgiu***.

Onde se encontra, afinal, a origem da burocracia? Pedrosa responde: na inexistência de controle da economia e da política pelas massas trabalhadoras. O que explicaria essa inexistência de controle? “... a falta de organizações autônomas e independentes das classes trabalhadoras e camponesas, de pequenos burgueses e massas consumidoras. Quer dizer: faltava às massas experiência socialista, consciência prática, capacidade de se dirigir e tomar em mãos a defesa de seus interesses e controlar os problemas da produção. Faltavam técnicos, faltavam condições objetivas favoráveis”***.

Mário Pedrosa dá a entender que as massas russas não estavam organizadas, englobando no conceito de massas os trabalhadores da cidade e do campo, os pequenos burgueses e as massas consumidoras. Ora, é curioso que Pedrosa se refira à falta de organizações autônomas dos trabalhadores numa revolução que justamente se caracterizou pela intensa criatividade nesse nível com a criação de sovietes de operários, soldados e camponeses além dos comitês de fábrica. A impressão deixada pelos textos de Pedrosa, em 46, é a de que a revolução teria sido prematura, visto que as massas não tinham experiência, capacidade para se dirigir. Contraditoriamente, Pedrosa é ardoroso defensor da idéia de que essa experiência e essa capacidade não são uma criação prévia à luta, mas que é no decorrer da revolução que as massas adquirem consciência dos seus objetivos. Na Revolução Russa, em particular, os trabalhadores mostraram possuir tal capacidade ao ocuparem as fábricas à revelia dos próprios bolcheviques, ao criarem suas próprias organizações revolucionárias que aos poucos foram sendo destruídas e transformadas em meros órgãos burocráticos dominados pelo partido bolchevique. Como entender, portanto, a análise de Pedrosa sobre a desorganização e inexperiência das massas russas e sua teoria da invenção organizadora durante o processo de luta?

No tocante à questão da tomada das fábricas pelos operários, por exemplo, contra a palavra de ordem bolchevique de "controle da produção", Pedrosa dá razão a Lenin contra os trabalhadores alegando a falta de preparo para dirigirem as empresas****. Embora Pedrosa defenda com veemência a idéia de que apenas através da experiência os trabalhadores adquirem capacidade para se auto-dirigir, no caso da Revolução Russa justifica a separação entre os que sabem - Lenin, "líder experimentado" — e os que não sabem - os trabalhadores. De modo geral, é possível observar que quando se trata da Revolução Russa, apesar de algumas ressalvas (quanto à teoria do partido, quanto às medidas burocráticas para combater a burocracia), Mário Pedrosa sempre justifica a política bolchevique e, sobretudo, as idéias de Lenin.

No texto que estamos examinando, Pedrosa refere-se também à falta de "condições

\footnotetext{
* VS, 7/6/46

** Id., ibid. Quanto à questão de ser a Rússia uma sociedade de classes em que existe um novo tipo de exploração escondida sob a propriedade coletiva, lembremos que desde 1933 Anton Ciliga formulara essa tese no seu Aus Pays du Grand Mensonge (Cf. 4, p.145). Ciliga vê a burocracia dos comunistas e especialistas como uma nova classe dirigente que vem substituir a nobreza e a burguesia. Também Bruno Rizzi, ex-comunista e ex-trotskista italiano, num ensaio de 1939, La Bureaucratisation du monde, publicado em francês, afirma que a URSS possui uma nova classe dominante, a burocracia, composta pelos membros do partido único que monopoliza o poder econômico, politico e cultural." “"... a URSS representa para nós um novo tipo de sociedade dirigida por uma nova classe. A propriedade está coletivizada e pertence a esta classe que organizou um novo sistema de produção. A exploraçào passa do domínio do individuo ao da classe"' $(8$, p. 61). Como sabemos, Lefort retoma essas idéias dando-Ihes um alcance teórico que não tinham nas suas formulações originais (C f. 4, p. 298,299). $* * *$ VS, $28 / 6 / 46$.

$* * * * \mathrm{VS}, 9 / 11 / 45$
} 
LOUREIRO, I.M. - A questão russa: seu lugar nas reflexões de Vanguarda Socialista. Trans/Form/Ação, São Paulo, 8:28-38, 1985 .

objetivas favoráveis" como um dos motivos que levaram à degenerescência da revolução e ao conseqüente fortalecimento da burocracia. A inexistência de tais condições significa o atraso econômico da Rússia e o isolamento da revolução, fatores que atuaram negativamente sobre o proletariado fazendo com que, numericamente fraco e sufocado pelo campesinato, não pudesse construir a economia russa com métodos socialistas*' Aos operários cabia o controle dos organismos políticos e econômicos, mas aqueles encontravam-se "sangrados, enfraquecidos, desfalcados**. Parte de sua vanguarda morrera na guerra civil e outra parte assumira cargos de direção no poder estatal, acabando absorvida pela burocracia administrativa. Além disso, o proletariado encontrava-se desencorajado pelo fracasso da revolução na Europa. Sob a ação desses motivos, vai, aos poucos, saindo da cena política e deixando nas mãos do partido e da sua burocracia a direção dos negócios.

Curiosamente, porém, em outro texto, Vanguarda Socialista*** imputa o advento do stalinismo à “derrota das forças operárias na Rússia, expressa pela supressão da democracia interna no partido e o aniquilamento dos elementos oposicionistas'”. Neste caso, a expressão derrota das forças operárias supõe que estas se encontravam organizadas e não, como fora dito no texto anterior, porque não tinham organizações autônomas. Se a derrota do operariado se exprime num primeiro momento pela proibição das frações no interior do partido e se uma dessas frações, a mais importante, a Oposição Operária (representante dos trabalhadores das fábricas), possuía um programa alternativo ao do partido bolchevique, isto significa que os trabalhadores estavam organizados de forma independente e foram golpeados. Nesta perspectiva, a derrota das Oposições de Direita e de Esquerda pelo grupo de Stalin é conseqüência do amordaçamento dos trabalhadores, efetuado já no período imediatamente pós-revolucionário.

Por um lado, para Vanguarda Socialista, o surgimento da burocracia deve-se à inexistência de controle, por parte das massas, sobre os organismos econômicos e políticos, explicada, em primeiro lugar, pela falta de organizações autônomas das próprias massas. Além disso, como para Vanguarda Socialista, no conceito de massas está englobada também a pequena burguesia, não basta que o proletariado esteja organizado, a revolução só vingará se a organização se estender às massas trabalhadoras assalariadas como um todo****. No caso da Rússia, o proletariado era a vanguarda da revolução, dirigido por outra vanguarda, o partido bolchevique. Uma vez a vanguarda derrotada, a revolução não foi adiante, porque não encontrou suporte no resto da população trabalhadora.

Por outro lado, entretanto, a inexistência do controle é também contraditoriamente explicada pela derrota do operariado, imputada unicamente à conjuntura: o isolamento da revolução, o atraso econômico do país que, com uma pequena indústria, levava o proletariado a ficar submerso pelo campesinato, a morte de parte da vanguarda proletária na guerra civil e a absorção de outra parte pela burocracia do Estado. A política antioperária dos bolcheviques, tal como é denunciada pela Oposição Operária, nunca é questionada por Vanguarda Socialista, pelo contrário, é mesmo justificada, como no caso da crítica à tomada das fábricas, vista como prematura.

\footnotetext{
* Apesar de falar no atraso da Rússia, Pedrosa não adota as teses mencheviques. No seu entender, estas não poderiam realizar-se devido a fraqueza orgânica da burguesia russa. Contudo, as previsões mencheviques verificaram-se: o socialismo, na medida em que era incerta a revolução internacional, era impossivel na Rússia, e isso levaria o governo a contradições insolúveis, como, de fato, se verificou (VS, 26/4/46).

***S, $19 / 4 / 46$

*** VS, "Novos Rumos", 20/9/46

**** Por isso, no Brasil, o partido socialista com que Vanguarda Socialista sonha englobaria o proletariado e a classe média.
} 
$\mathrm{Na}$ mesma linha de justificativa da política bolchevique, Vanguarda Socialista faz contínuas referências elogiosas à política leninista do “capitalismo de Estado",* acreditando, assim como Lenin, que este seria uma via de acesso ao socialismo, desde que controlado pelos trabalhadores. Nas suas palavras: “O capitalismo de Estado pode ser uma forma de transição do capitalismo para o socialismo dentro de determinadas condições políticas e sociais. Lenin o considerou como uma forma de transição ao sair da guerra civil desde que se pudesse transportar para a Rússia a organização técnicoeconômica do capitalismo alemão da época imperial, controlado e canalizado pelo estado operário - ou pelo menos o estado dominado pelo partido bolchevique em sua fase revolucionária. No entanto, a evolução econômica e histórica, malgrado as garantias e contrapesos previstos por Lenin, superou estas formas puramente políticas de controle (estado soviético, regime dos sovietes, partido bolchevique) e levou a Rússia ao capitalismo de estado totalitário atual', ***

Afinal, no que consistia a política leninista do capitalismo de Estado? Para Lenin, a Rússia devia aprender, na esfera da economia, com os países capitalistas avançados, transpondo para aquele país a "racionalização" capitalista, vista como um meio para a construção do socialismo. A extrema centralização alcançada pelo capitalismo monopolista de Estado, modelo alemão, é encarada como progressista e como uma forma a ser utilizada pelo Estado “proletário", Acreditava que as conquistas do grande capitalismo deveriam ser preservadas e que teriam um fim socialista porque submetidas aos sovietes proletários. Tal política, contudo, está indissoluvelmente ligada a um discurso taylorista e autoritário*** consistindo na exaltação da obediência, da produtividade, da disciplina e do espírito de sacrifício dos trabalhadores a que Vanguarda Socialista não faz a menor alusão. Quando Lenin proclama que é necessário aprender com o capitalismo de Estado alemão "não se interroga nunca sobre uma possível relação entre organização industrial e sistema político, entre disciplina do trabalho e formas sociais de autoridade. Toma uma grotesca combinação de burocracia e militarismo a ponto de se desintegrar como a mais completa expressão da razão científica', (7, p. 82).

Vanguarda Socialista, ao tomar como possível via de transição para o socialismo a proposta leninista de capitalismo de Estado, não leva em conta a realidade russa sob o ef eito concreto dessa proposta, mas atém-se a um capitalismo de Estado ideal onde, teoricamente, haveria autonomia dos trabalhadores e controle dos grandes organismos econômicos. Não podemos esquecer que a Oposição Operária de Alexandra Kollontai, a que Mário Pedrosa se refere e à qual dá crédito como crítica de primeira hora contra a burocracia, combateu a política do capitalismo de Estado, defendida pela direção bolchevique, política incompatível com a emancipaçãc autônoma dos trabalhadores defendida tanto pela oposição ao partido bolchievique quanto pela própria Vanguarda Socialista. Essa ambigüidade, porém, não parece incomodar o grupo de Vanguarda Socialista, provavelmente porque desconhecia os detalhes da discussão histórica. A defesa da política leninista do capitalismo de Estado feita pelo jornal deve-se possivelmente ao fato de que nela se fala em controle pelos trabalhadores como meio de evitar

\footnotetext{
* Sobrea politica leninista do capitalismo de Estadover 1, p. 421, 422 e 3, p. 103, 1()4.

** VS. "Novos Rumos"'. Pedrosa utiliza essa terminologia embora saiba que outros preferem chamar o Estado soviétivo de “socialısmo de Estado" já que todos os meios de produção são propriedade do Estado. Porém, não concorda com essa denominação visto que ali se verifica a "exploração do homem pelo homem"' (VS, 24/5/46).

*** Quando Lenin declara que os russos devem aprender com o capitalismo de Estado alemão, faz afirmações como esta: "Nosso dever consiste em nos aplicarmos com todas as nossas forças a assimilá-lo, não pouparmos os processos ditatoriais para implantá-lo na Rússia ainda mais depressa do que fez Pedro I com os costumes ocidentais na velha Rússia bárbara, sem recuar perante o emprego de métodos bárbaros contra a barbárie', (7, p. 84).
} 
o crescimento desmesurado do Estado e da burocracia e, nessa medida, recusa o capitalismo de Estado tal como se tornou vigente sob Stalin.

No que consiste, então, para Vanguarda Socialista, o capitalismo de Estado da época stalinista? Constata que a estatização da propriedade, tanto na agricultura quanto na indústria, permitiu enorme desenvolvimento das forças produtivas e criou, ao mesmo tempo, uma diferenciação social que deu à economia estatizada sua base de classe necessária: "A burocracia transformou-se durante estes anos numa classe com sua ideologia à parte"**. A burocracia apodera-se do aparelho estatal, extremamente centralizado e usufrui da propriedade estatizada, assumindo, ao mesmo tempo, a responsabilidade pelo desenvolvimento das forças produtivas. O Estado, proprietário dos meios de produção, transforma-se numa entidade autônoma, no sentido de que não representa nem os interesses do campesinato nem os do proletariado, vivendo da exploração de classe, no campo e na cidade. "É a esse processo de diferenciação social, de exploração social na base da estatização dos meios de produção, que chamo de capitalismo de Estado, $* *$

Neste ponto, portanto, Pedrosa e o grupo de Vanguarda Socialista discordam dos trotskistas. Para eles, a Rússia não é um Estado operário nem mesmo “degenerado”. "O que se verifica ali são formas de exploração capitalista coletiva e neofeudais, por intermédio do Estado totalitário, ou seja, uma forma própria do capitalismo de Estado, $* * *$. No seu entender, a concepção trotskista é puramente jurídica e por isso falsa, na medida em que toma como critério decisivo para caracterizar uma determinada forma de Estado a forma da propriedade - coletiva ou privada. No entender do grupo, é o controle da propriedade estatizada e não a sua posse que determina a existência de uma nova classe que dispõe dessa propriedade em seu benefício.

Como dissemos anteriormente, Mário Pedrosa justifica a política bolchevique, não só no que concerne à proposta do capitalismo de Estado, como acabamos de ver, mas também no que se refere à questão da organização revolucionária, na situação particular da Rússia. Embora critique a concepção leninista do partido-vanguarda porque "marcha inexoravelmente para o partido único, para tornar-se instrumento de um regime totalitário sempre possível" ***, nas circunstâncias russas, o partido bolchevique, centralizado e autoritário, se explicava na luta clandestina contra o czarismo. No entanto, ao mesmo tempo, reconhece que já no início da revolução o que havia na Rússia não era a ditadura do proletariado mas a ditadura do partido sobre o proletariado, a ditadura de uma minoria de revolucionários jacobinos. Porém, neste caso específico, também a ditadura do partido é legítima: "Porque o partido naquela época não era somente a vanguarda mais esclarecida das massas, como tinha uma grande concepção política a realizar. Ele tinha a visão histórica, de conjunto, da marcha da revolução russa para um regime socialista, quando surgisse na Alemanha, na Europa ocidental, a revolução proletária. Armados dessa idéia os bolcheviques se defenderam de todas as maneiras para se manter sozinhos no poder. Na realidade, isso representava já a primeira quebra na concepção de Lenin dum governo operário e camponês, $* * * * *$

A ditadura do partido se explica porque os bolcheviques eram a vanguarda que tinha um programa de transição para o socialismo cujo sucesso dependia da revolução na

\footnotetext{
*VS, 24/5/46.

** VS, $24 / 5 / 46$

***VS, “Novos Rumos", 20/9/46.

$* * * *$ VS, $26 / 7 / 46$

***** Id., ibid.
} 
LOUREIRO, I.M. - A questão russa: seu lugar nas reflexões de Vanguarda Socialista. Trans/Form/Ação, São Paulo, 8:28-38, 1985.

Europa. Essa, que era uma condição sine qua non para a instauração do socialismo na Rússia, não ocorreu. Resultado: defasagem entre as idéias "na cabeça” dos líderes e a realidade "objetiva" e conseqüente vitória da burocracia, adepta do "realismo político',

Em suma, nas circunstâncias históricas precisas em que a Rússia se encontrava, a política bolchevique se justifica: a burocratização do regime tem seu início em 1921 quando são eliminadas as frações no interior do partido, ao mesmo tempo, diz Mário Pedrosa, em que os bolcheviques se viram na "necessidade dolorosa" de liquidar Kronstadt. As circunstâncias obrigam os bolcheviques a se isolar no poder, a tomar posições contra a sua própria vontade. Portanto, a degenerescência da revolução foi fruto da conjuntura particular em que a Rússia se encontrava, o próprio Stalin sendo "apenas o instrumento de uma evolução quase irresistível", devendo ser combatido não por ter traído ou causado a degenerescência da revolução, mas porque se tornou o portavoz de determinados interesses, fruto de condições objetivas que não criou. Numa palavra, Mário Pedrosa justifica a política do partido bolchevique durante a revolução uma vez que "as condições objetivas da sociedade russa" acabaram levando Lenin, contra a sua vontade, a criar "as premissas para o reino posterior de Stalin e a consolidação... do Capitalismo de Estado atual" * .

A o fazer este tipo de análise, Mário Pedrusa inspira-se em Rosa Luxemburgo que, em seu opúsculo sobre a Revolução Russa, após criticar as medidas antidemocráticas adotadas pelos bolcheviques, acaba por legitimá-las, ao dizer: “Tudo o que se passa na Rússia se explica perfeitamente: é uma cadeia inevitável de causas e efeitos, cujos pontos de partida e de chegada são a carência do proletariado alemão e a ocupação da Rússia pelo imperialismo alemão. Seria exigir de Lenin e seus amigos uma coisa sobrehumana pedir-lhes que, em semelhantes condições, criassem por uma espécie de mágica a mais bela das democracias, a mais exemplar ditadura do proletariado e uma economia socialista florescente. Com sua atitude resolutamente revolucionária, sua energia sem exemplo e sua inabalável fidelidade ao socialismo internacional, eles fizeram quanto possível foi em condições tão terrivelmente difíceis. O perigo começa no ponto onde, fazendo da necessidade virtude, eles criaram uma teoria da tática imposta por estas condições fatais, pretendendo recomendá-la ao proletariado internacional como o modelo da tática socialista... O que importa é distinguir na política dos bolcheviques o essencial do acessório, a substância do acidente' (5, p. 160, 161).

Se Rosa Luxemburgo justifica a política bolchevique é para se contrapor ao imobilismo da social-democracia alemã que, ao emperrar a luta revolucionária em seu país, isolava os bolcheviques levando-os a uma prática autoritária em nome das necessidades da preservação do Estado operário. A admiração de Rosa pela energia revolucionária dos bolcheviques e a constatação da responsabilidade da social-democracia alemã na “traição" ao proletariado russo não a impede, contudo, de criticar a política antidemocrática daqueles.

\footnotetext{
* VS, 24/1/47. Mário Pedrosa, na medida em que, ao mesmo tempo, critica e dá razão à política bolchevique, exprime o impasse a que esta se viu coagida, dividida entre o programa revolucionário e a conjuntura contra-revolucionária que levava a uma política antioperária e antidemocrática. A frase de Pedrosa, os bolcheviques viram-se na "necessidade dolorosa" de liquidar Kronstadt, exprime bem essa tragédia. Aqueles afirmavam que o momento exigia o massacre dos marinheiros revoltosos, "orgulho e glória da revolução", mesmo contra a sua vontade, e o mais irônico nesse episódio é que a própria Oposição Operária aprovou o massacre. Contudo a crítica/justificação simultânea por parte de Pedrosa restringe-se ao período imediatamente pós-revolucionário. Em relação ao stalinismo, contrariamente a Trotsky, não há a menor vacilação. Tanto que a palavra de ordem de "defesa incondicional da Rússia"” é sempre criticada, tendo servido de divisor de águas entre ele e o trotskismo.
} 
LOUREIRO, I.M. - A questão russa: seu lugar nas reflexões de Vanguarda Socialista. Trans/Form/Ação, São Paulo, 8:28-38, 1985.

A crítica, porém, é precisa: as necessidades do momento, as contingências conjunturais forçaram-nos a uma política adaptada a essas necessidades e, por isso mesmo, constitui erro palmar querer transformar o que foi fruto da contingência em norma universalmente válida no tempo e no espaço. Simultaneamente, Rosa não contrapõe à crítica ao autoritarismo bolchevique uma defesa da democracia em abstrato: aceita o emprego da violência contra os sabotadores da revolução, condenando, todavia, "todo arbitrário que ultrapasse essa necessidade absoluta de autodefesa revolucionária' (6, p.126). O arbitrário, no caso da Revolução Russa, consiste na abolição da liberdade política por parte dos bolcheviques.

Rosa declara que apenas uma vida pública plenamente livre e democrática, na qual haja participação de "toda a massa do povo", em que esta massa exerça controle sobre os dirigentes, pode permitir que os mil problemas que surgem no processo de transformação socialista sejam solucionados. Caso contrário - a democracia e a liberdade amordaçadas - , a criatividade das massas não podendo se exercer, o resultado será o domínio de alguns intelectuais, dos funcionários do novo governo sobre "toda a massa do povo". Isto é, só a total e completa liberdade será uma barreira eficaz contra a burocracia $(6$, p. 127$)$.

Como podemos perceber, Rosa Luxemburgo acentua o papel da escolha política, da vontade, no fazer histórico. Em primeiro lugar, foi a prática imobilista da socialdemocracia alemã que determinou o isolamento da Revolução Russa e as conseqüências catastróficas que daí advieram; em segundo lugar, os bolcheviques, ao entrarem pelo caminho do terror para implantar o socialismo acabaram levando água ao moinho da burocracia. Neste ponto, porém, não há saída, segundo Rosa; os bolcheviques são coagidos pela conjuntura a trilhar esse caminho. Aqui aplica-se como uma luva a frase de Marx de que "os homens fazem sua própria história mas não a fazem como querem,".

Eis o pano de fundo da análise pedrosiana da Revolução Russa. Contudo, a ênfase, tanto do discurso de Rosa Luxemburgo quanto do de Mário Pedrosa, é posta no seguinte: o que ocorreu na Rússia não deve ser tomado como modelo para outros países, uma vez que o "socialismo... não é mais do que um produto histórico, nascido da própria experiência e da situação concreta', (6, p. 127) não havendo, portanto, receitas prontas para serem aplicadas em toda parte e em qualquer tempo. O alvo de Pedrosa são os partidos comunistas do mundo inteiro, subservientes à política ditada pelo partido comunista russo, subserviência que, segundo ele, foi responsável pelo "rumo trágico" que tomaram os acontecimentos mundiais na Europa Central e na Alemanha (Cf. 6, p. 119). É na tentativa de traçar uma linha socialista independente do bolchevismo e do stalinismo que Mário Pedrosa, ao analisar a Revolução Russa, faz suas as palavras de Rosa Luxemburgo: "Entregar-se a um estudo crítico da Revolução, sob todos os seus aspectos, é o melhor meio de educar a classe operária, tanto alemã como internacional, diante das tarefas que lhe impõe a atual situação.' (5, p. 118). 
LOUREIRO, I.M. - A questão russa: seu lugar nas reflexões de Vanguarda Socialista. Trans/Form/Ação, São Paulo, 8:28-38, 1985.

LOUREIRO, I.M. - The Russian question and its place in Vanguarda Socialista. Trans/Form/Aç̃o, São Paulo 8:28-38, 1985.

ABSTRACT: Vanguarda Socialista, a newspaper edited by Mário Pedrosa in Rio de Janeiro from 1945 to 1948 elaborates a socialist and democratic political proposal as an alternative to the bolshevik conception, which was believed surpassed by history. The "Russian question"' lies thus at the center of the group's preoccupations. This paper tries not only to analyse the newspaper's explanation for the origins of bureaucracy in the USSR, bringing to light the contradictions which run through it, but also to establish the group's affiliation to Rosa Luxemburg's ideas, in the attempt to clarify those contradictions.

KEY-WORDS: Revolution; Leninism; Stalinism; bureaucracy; socialism; democracy.

\section{REFERÊNCIAS BIBLIOGRÁFICAS}

I. BETTELHEIM, C. - Les luttes de classes en $U R S S$ (première période - 1917-1923). Paris, Maspero/Seuil, 1974.

2. CASTORIADIS, C. - L'expérience du mouvement ouvrier. Paris, Ed. 10/18, 1974. v. 2.

3. COHEN, S.F. - Bujarin y la revolución bolchevique. Madrid, Siglo Veintiuno, 1976.

4. LEFORT, C. - Eléments d'une critique de la bureaucratie. Paris, Gallimard, 1979.

5. LUXEMBURG, R. - A Revolução Russa. In: PEDROSA, M. - A Crise mundial do impe- rialismo e Rosa Luxemburg. Rio de Janeiro, Civilização Brasileira, 1979.

6. PEDROSA, M. - A crise mundial do imperalismo e Rosa Luxemburg. Rio de Janeiro, Civilização Brasileira, 1979.

7. QUERZOLA, J. - Le chef d'orchestre à la main de ferleninisme et taylorisme. Recherches $n .^{\circ}$ $32 / 33,1978$.

8. RIZZI, B. - La burocratización del mundo. Barcelona, Península, 1980. 